\title{
Histopatoloji Görüntülerde Derin Öğrenme Yöntemleri ile Çekirdek Segmentasyonu
}

\author{
Ertuğrul Menteșe*, Emrah Hançer ${ }^{2}$ \\ ${ }^{1}$ Burdur Mehmet Akif Ersoy Üniversitesi, Sosyal Bilimler Enstitüsü, Yönetim Bilişim Sistemleri Bölümü, Burdur, Türkiye (ORCID: 0000-0001-6290-9576) \\ ${ }^{2}$ Burdur Mehmet Akif Ersoy Üniversitesi, Teknoloji Fakültesi, Yazılım Mühendisliği Bölümü, Burdur, Türkiye (ORCID: 0000-0002-3213-5191)
}

(International Symposium on Multidisciplinary Studies and Innovative Technologies (ISMSIT) 2020 - 22-24 Ekim 2020)

(DOI: $10.31590 /$ ejosat.819409)

ATIF/REFERENCE: Menteşe, E. \& Hançer, E. (2020). Histopatoloji Görüntülerde Derin Öğrenme Yöntemleri ile Çekirdek Segmentasyonu. Avrupa Bilim ve Teknoloji Dergisi, (Özel Sayı), 95-102.

$\ddot{O} z$

Histopatoloji organlar, dokular ve hücreler üzerinde oluşan değişikliklerin mikroskop üzerinde incelenmesidir. İncelenmesi gereken dokular, mikro kesiciler tarafindan incelenmeye uygun kalınlıkta kesilmektedir. Kesilen dokulara bazı boyama teknikleri uygulanmaktadır. Hematoksilin-Eozin(H\&E) yöntemi, en yaygın kullanılan boyama tekniğidir. Hematoksilin, hücre çekirdeklerini mavi tonlarına, eozin ise sitozplazmaları pembe tonlarına boyamaktadır. Boyanan kesitler, uzman tarafindan değerlendirilmektedir. Histopatoloji görüntüleri kanser hastalığının tespiti ve kanser durumunun derecelendirilmesi için oldukça önemli rol oynamaktadır. Bu görüntülerdeki çekirdeklerin daha kolay ve başarılı analiz edilmesi için literatürde birçok çalışma bulunmaktadır. Bu çalışmalar son zamanlarda derin öğrenmenin semantik segmentasyon alanına odaklanmış ve ilgili yöntemlerle umut verici sonuçlar elde edilmiştir. Her ne kadar çekirdek segmentasyon alanında derin öğrenme yöntemleriyle çeşitli çalışmalar gerçekleştirilmiş olsa da ilgili derin öğrenme mimarilerinin birbiriyle karşılaştırmalı analizini gerçekleştiren kapsamlı bir çalışma literatürde bulunmamaktadır. Bu çalışmada popüler derin öğrenme yöntemlerinden olan U-Net, SegNet, FCN ve DeepLabV3+ olmak üzere dört farklı mimari, çekirdek segmentasyonuna uygulanıp ve gerekli analizler yapılarak en fazla faydayı sağlayan mimariyi ortaya çıartmak amaçlanmıştır. Çalışmada uygulanan genel çekirdek segmentasyonu metodolojisi üç aşamadan oluşmaktadır: 1) Görüntü verileri eğitilmeden önce CLAHE algoritması ile ön işlemden geçirilip daha kaliteli görüntüler elde edilmeye çalışılmıştır; 2) CLAHE algoritması ile ön işlemden geçirilen görüntü verileri kullanılarak ilgili derin öğrenme mimarisi ile eğitilmiştir; 3) Eğitilen model test görüntüleri üzerinde global doğruluk ve ortalama IOU gibi kriterler kullanılarak geçerleme işlemi gerçekleştirilmiştir. Deneysel çalışmalar için içerisinde birden fazla organın histopatoloji görüntülerini bulunduran MoNuSeg veri seti kullanılmıştır. Gerçekleştirilen deneysel çalışmalar sonucunda, DeepLabV3+ mimarisi diğer mimarilere oranla çok daha kısa sürede işlemini tamamlamış ve diğer mimarilerden gözle görülür ölçülde daha iyi performans elde etmiştir.

Anahtar Kelimeler: Çekirdek segmentasyon, DeepLabV3+, U-Net, SegNet, FCN, histopatoloji görüntüler.

\section{Nucleus Segmentation with Deep Learning Approaches on Histopathology Images}

\begin{abstract}
Histopathology is the examination of changes on organs, tissues and cells on a microscope. Tissues to be examined are cut by microcutters in a suitable thickness for examination. Some painting techniques are applied to the cut tissues. The Hematoxylin-Eosin (H\&E) method is the most commonly used staining technique. Hematoxylin stains cell nuclei in shades of blue, and eosin stains cytosplasms in shades of pink. Stained sections are evaluated by the expert. Histopathology images play an important role in detecting cancer disease and grading cancer status. There exist many studies in the literature to analyze nucleus in these images more easily and successfully. These studies have recently focused on the semantic segmentation area of deep learning and promising results have been obtained using the corresponding methods. Although various works have been conducted with deep learning methods in the field of nucleus segmentation, there is no comprehensive work in the literature that makes comparative analysis of related deep learning architectures. This study aims to apply four different well-known deep learning architectures, which are U-Net, SegNet, FCN, and
\end{abstract}

${ }^{*}$ Sorumlu Yazar: Burdur Mehmet Akif Ersoy Üniversitesi, Sosyal Bilimler Enstitüsü, Yönetim Bilişim Sistemleri Bölümü, Burdur, Türkiye, ORCID: 0000-0001-6290-9576, ertugrul.mnts@gmail.com 
DeepLabV3+, to nuclei segmentation and determine the most suitable one for this process. The general nucleus segmentation methodology applied in the study consists of three stages; 1) Before training the image data, it is pre-processed with the CLAHE algorithm to obtain better quality images; 2) The pre-processed image data using the CLAHE algorithm is trained with the relevant deep learning architecture; 3 ) The trained model is verified on test images using criteria such as global accuracy and average IoU. For experimental analysis, MoNuSeg data set containing histopathology images of more than one organ is used. According to the results, DeepLabV3+ architecture completes its operation in a much shorter time than other architectures and achieves a noticeably better performance than the rest of the architectures.

Keywords: Nucleus segmentation, DeepLabV3+, U-Net, SegNet, FCN, histopathology images.

\section{Giriş}

Görüntü temel olarak çeşitli tonlardaki piksellerin biraraya geldiği bir yapıdır ve teknolojik sistemler tarafından kullanılabilmesi için çeşitli işlemlerden geçirilmesi gerekmektedir. Bu işlemlerden en çok kullanılanlardan birisi de segmentasyon işlemidir. Segmentasyon, bir görüntüdeki her bir pikselin mevcut sınıf etiketlerinden birine sınıflandırma işlemidir. Temel olarak iki çeşit segmentasyon vardır (Garcia-Garcia vd., 2017): 1) Birey (Instance) Segmentasyon: Bir nesneye ait herbir bireyin farklı bir sınıf etiketine atanması işlemdir. Örneğin, bir görüntüde yer alan üç köpeğe üç farklı etiket atanır; 2) Semantik Segmentasyon: Belirli bir nesneye ait bireylere ait piksel aynı sınıf etiketine atanır. Örneğin, bir görüntüde yer alan üç köpeğe aynı sınıf etiketi atanır. Bu çalışmada semantik segmentasyon üzerine yoğunlaşılacaktır.

Semantik segmentasyonun uygulama alanlarından birisi de hematoksilen ve eozin (H\&E) boyalı histopatoloji görüntülerdir. Histopatoloji görüntülerde bazı zorluklarla karşılaşılmaktadır. Bunlardan birincisi görüntülerin farklı cihazlarda taranması ve farklı boya markalarının kullanılmasından kaynaklanan renk dağılım farklılıklarıdır. Bir diğeri ise çekirdeklerin tespiti ve segmentasyon işlemidir. Çekirdeklerin tespiti ve segmentasyonu, hastalıkların tanımlanması ve derecelendirilmesi için kullanılacak hücresel morfoloji özelliklerini ve dokuları çıkartmak için önemli rol oynamaktadır. Çekirdekler, kanser derecelendirilmesinde ve hücre sayımında önemli bir parametredir. Ancak çekirdeklerin boyutlarının çeşitlilik göstermesi, iç içe geçmesi, farklı renklerde tanımlanması ve iyi boyanmamış olması tespit ve segmentasyon işlemini oldukça zorlaştırmaktadır. Çekirdek tespit ve segmentasyon işleminde watershed (Zhang vd., 2010), morphology (Park vd., 1998), thresholding (Tobias ve Seara, 2002), k-means (Ray ve Turi, 1999) ve active contour models (ACMs) (Derraz vd., 2004) gibi bilinen klasik yöntemler uygulanmıştır. Ancak ilgili klasik yöntemler ile istenen başarıya tam anlamıyla ulaşılamamıştır.

İlgili klasik yöntemlerin yetersiz kalması sebebiyle son zamanlarda semantik segmentasyon alanında da başarıyla uygulanmaya başlanan derin öğrenme yöntemleri çekirdek tespit ve segmentasyon işleminde araştırmacılar tarafından kullanılmaya başlanmıştır. Ronneberger ve arkadaşları (Ronneberger vd., 2015), yaptıkları çalışmada biyolojik mikroskopi görüntülerini bölümlere ayırmak için derin öğrenme mimarilerinden olan U-Net'i önerdi. Moeskops ve arkadaşları (Moeskops vd., 2016), yaptıkları çalışmada MR beyin görüntülerinde altı dokuyu, MR gögüs görüntülerinde pektoral kası ve kardiyak BTA'da koroner arterleri içeren çoklu görüntü segmentasyonu için tek bir CNN mimarisinin kullanılmasını önermiştir. Jia ve arkadaşları (Jia vd., 2017), yaptıkları çalışmada histopatoloji görüntülerinde, görüntüden görüntüye segmentasyonu için FCN tabanlı bir yaklaşım önermiştir. Zhou ve arkadaşları (Zhou vd., 2018), çoklu organ tespiti için önerilen bir segmentasyon tekniğinin performans analizini yapmıştır. Roth ve arkadaşları (Roth vd., 2018), yaptıkları çalışmada 3 boyutlu FCN mimarilerini her çoklu organ görüntüsünde arterleri, portal venleri, karaciğeri, dalağı, mideyi, safra kesesini ve pankreası tanımlamak için karın bilgisayarlı tomografisini otomatik olarak segmentlere ayırmakta kullanmıştır. Wang ve arkadaşları (Wang vd., 2018), yaptıkları çalışmada eğitim için iki organ ek açıklaması kullanarak fetal MR(Manyetik Rezonans) görüntülerinde birden fazla organın 2D segmentasyonunu önermektedir. Her ne kadar derin öğrenme yöntemleriyle çekirdek segmentasyonu alanında literatürde çeşitli çalışmalar yapılmış olsa da ilgili yöntemlerin kapsamlı karşılaştırmalı analizini gerçekleştiren bir çalışma henüz bulunmamaktadır.

Bu çalışmanın amacı, mevcut bilinen derin öğrenme mimarilerini kullanarak bir çekirdek segmentasyon metolojisi oluşturmak ve ilgili mimarilerin çeşitli kriterler üzerinden karşılaştırmalı analizini gerçekleştirmektir. Bu amacı gerçekleştirmek için geliştirilen metodoloji üç aşamadan oluşmaktadır. İlk aşamada görüntülerin CLAHE algoritması (Reza, 2004) ile ön işlemden geçirilerek istenmeyen gürültülerden arındırılması hedeflenmiştir. İkinci aşamada ön işlemden geçrilen görüntülerin semantik segmentasyon alanında başarıyla uygulanan U-NET (Ronneberger vd., 2015), SegNet (Badrinarayanan vd., 2017), FCN (Shelhamer vd., 2017) ve DeepLabV3+ (Chen, Papandreou, vd., 2018) mimarileri ile eğitilmesi hedeflenmiştir. Son aşamada eğitilen modellerin test görüntü verileri üzerinde bazı değerlendirme kriterleri ile analizi gerçekleştirilmiştir.

\section{Materyal ve Metot}

\subsection{Veri Seti}

Kumar ve arkadaşları (Kumar vd., 2017), 2017'de birçok hastaneden topladıkları ve yedi farklı doku türünden oluşan bir veri seti yayımladı. Bu veri seti, $40 \mathrm{kez}$ büyütülmüş H\&E boyalı doku görüntülerinde 21.000'in üzerinde elle açılklanmış çekirdek içermektedir. 18 farklı hastaneden, hastanın ve hastalığın durumuna göre özellikleri eklenerek toplanan bu veri seti, açıklamalı çekirdek veri setlerinin en büyük örneklerinden biridir. Veri seti iki parçaya ayrılmıştır:

1) Ĕ̆itim Seti: Birçok eğitim setinde ise hastalardan birden fazla alt görüntü çıkarılmış ve bu da çeşitliliği azalmıştır. Diğer eğitim setlerinden farklı olarak bu eğitim setinde her hastanın sadece tek bir 1000 x 1000 piksellik görüntüsü ve toplamda 30 görüntü bulunmaktadır. Bu da çeşitliliğin artmasına sağlamıştır. Çekirdeklerin açıklamaları XML dosyaları ile belirtilerek üst 
üste binen çekirdeklerin kolayca fark edilebilmesi amaçlanmıştır. Bu sayede çekirdek olan ve çekirdek olmayan bölgelerin ayrılması kolaylaştırılmış̧ır.

2) Test Seti: Her bir görüntünün 1000 x 1000 piksel olduğu bu sette toplam 14 görüntü bulunmaktadır. 7 farklı doku türünden oluşan bu set, her biri elle açıklanan 7.223 çekirdekten oluşmaktadır. Eğitim setinden farklı olarak, akciğer ve beyin doku örnekleri bulundurmaktadır.

İlgili veri setine ait bilgiler organlar üzerinden Tablo 1'de sunulmuş olup, bu veri seti ile ilgili yapılan çalışma ve analizlere (Kumar vd., 2020) ‘ten erişilebilir.

Tablo 1. Veri setindeki ĕgitim ve test verilerinin dă̆llımı

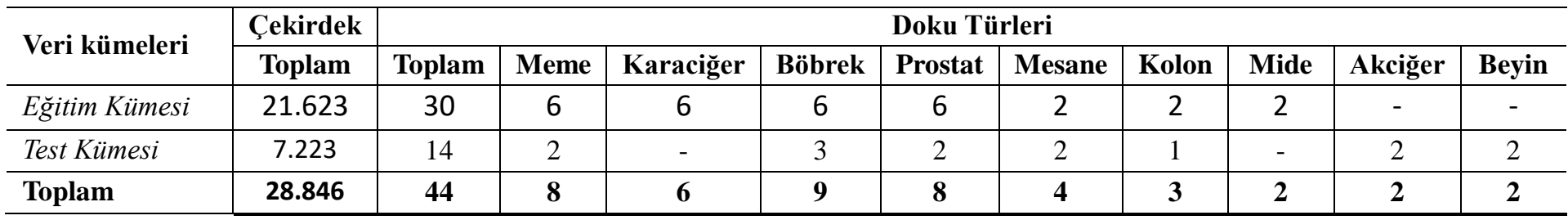

\subsection{Semantik Segmentasyon Yöntemleri}

Semantik segmentasyon, bir görüntüdeki her pikseli bir sınıf etiketine eşleştirme sürecini ifade eder. Bu sınf etiketleri, araba, çiçek, mobilya vb. herhangi bir nesneye veya olguya ait olabilir. Semantik segmentasyonu piksel düzeyinde görüntü sınıflandırması olarak da ifade edebiliriz. Örneğin, çok sayıda ağacin bulunduğu bir görüntüde, segmentasyon tüm ağaçları ağaç nesnesi olarak etiketliyecektir. Böylece bir bölgedeki ağaç veya yeşillik alan yoğunluğunu tespit etmek mümkün olacaktır. Başlıca uygulama alanlarından bazıları otonom araçlar, insan-bilgisayar etkileşimi, roboti uygulamalar ve medikal resim analizidir. Örneğin, kendi kendine giden arabalarda ve robotikte semantik segmentasyon çok önemlidir çünkü modellerin çalıştıkları ortamdaki bağlamı anlaması önemlidir.

Bu çalışmada kullanılan başlıca semantik segmentasyon yöntemleri alt bölümlerde ele alınmıştır.

\subsection{1. $\mathrm{U}$-Net}

U-Net günümüzde biyomedikal görüntü segmentasyonunda en popüler ve başarılı derin öğrenme modellerinden biridir. Evrişimli sinir ağlarından türetilmiştir. Kodlama ve kod çözme bölümlerinden oluşur. Kodlama kısmı, VGG (Simonyan ve Zisserman, 2015) tarzı evrişimli sinir ağından oluşur. Her bir katmanın 0.1 sızıntı faktörü olan düzeltilmiş doğrusal birimleri (ReLU) kullanıp ve ortaya çıkan görüntünün çözünürlüğünü ikiye katlayıp maksimum havuzlama işleminin tekrarlayarak uygulanmasından oluşur. Maksimum havuzlama adımında dönüştürmelerle özellik kanalı ikiye katlanır. Kod çözme kısmındaysa, özellik kanalını yukarı evrişimin tekrarlanarak uygulanmasından oluşur. Bu adımda özellik kanalının sayısı yarıya iner. 0.1 oranında sızıntı yapan ReLu'larla, karşılık gelen çözünürlük ve iki evrişimli birleştirilir (Livne vd., 2019). İlgini mimari Şekil 1’de sunulmuştur.

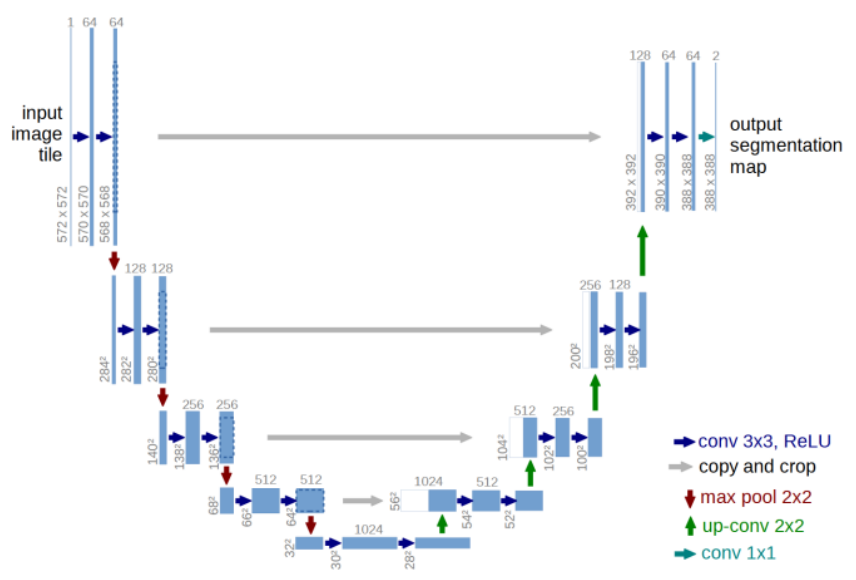

Şekil 1. U-net Mimari Yapısı (Ronneberger vd., 2015)

\subsubsection{SegNet}

SegNet, piksel açısından semantik segmentasyon için performansı yüksek olan modellerden biridir. SegNetin kodlayıcı kısmı topolojik olarak VGG16'nın evrişimli katmanlarıyla aynıdır (Simonyan ve Zisserman, 2015). SegNet, her kodlayıcıya karşıllk kod çözücüye sahip bir kod çözücü ağdır. Son kod çözücü, her piksel için birbirinden bağımsız olarak sınıflandırma üretir. Bunun için soft-max sınıflandırıcısını kullanır (Badrinarayanan vd., 2017). İlgini mimari Şekil 2'de sunulmuştur. 


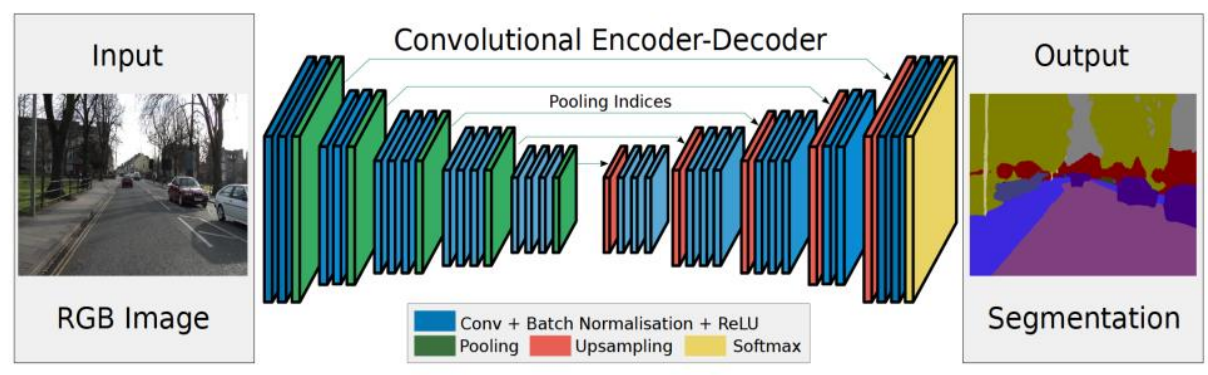

Şekil 2. SegNet Mimari Yapısı (Badrinarayanan vd., 2017)

\subsubsection{DeepLabV3+}

İlk hali 2015 yılında Google aracılığıyla Chen ve arkadaşları (Chen et al., 2015) tarafından yayınlanan mimari sürekli geliştirilmektedir. DeepLab, evrişimden önce özellikleri yeniden örneklemeye yarayan Boşluklu uzamsal piramit havuzlaması (Atrous spatial pyramid pooling) aracılığıyla nesneleri birden çok ölçekte segmentlere ayırır. Bu, farklı ölçekleri hesaba katmaya yardımcı olur ve doğruluğu arttırır. Ardından, özellik haritalarını kademeleri olarak azaltan ve daha yüksek anlamsal bilgileri yakalayan bir kodlayıcı modülü ile uzamsal bilgileri kurtaran bir kod çözücü eklenmiştir. Bununla genişletilen DeepLabV3, son hali olan DeepLabV3+ halini almıştır (Chen, Zhu, vd., 2018). DeepLabV3+ mimarisinin genel şeması Şekil 3 'te sunulmuştur.

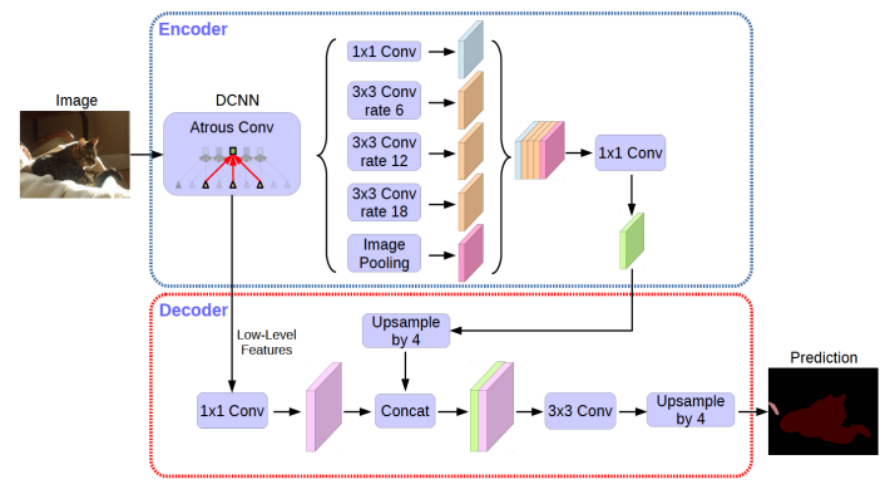

Şekil 3. DeebLapV3+ Mimari Yapısı (Chen, Zhu, vd., 2018)

\subsubsection{FCN}

Bir evrişimli ağdaki her veri, $h * w^{*} d$ boyutunda üç boyutlu diziden oluşmaktadır. Bahsedilen $h$ ve $w$, uzaysal boyutlar olan yükseklik ve genişliktir, $d$ ise özellik veya kanal boyutudur. İlk katmanda, piksel boyutları $h$ ve $w$ olan, renk kanalı $d$ olan görüntü vardır. 3 farklı biçimde kullanılabilmektedir.

FCN-32: Dönüştürülmüş bir evrişim katmanı aracılığıyla doğrudan conv7 kısmına geçerek segmentasyon haritasını üretir.

FCN-16: pool4 ile conv7'den 2x yukarı örneklenmiş tahmini toplar. Ardından dönüştürülmüş bir evrişim katmanıyla segmentasyon haritası üretir.

FCN-8: pool4 ile 2x yukarı örneklenmiş conv7'yi toplayıp, yukarı örnekleme yapar. Bu örneklemeyle pool3'ü toplar. Ortaya çıkan özellik haritalarına dönüştürülmüş evrişim katmanı uyguladıktan sonra segmentasyon haritasını elde eder. Diğerlerine göre performansı daha yüksektir (Shelhamer vd., 2017). İlgini mimari Şekil 4'de sunulmuştur.

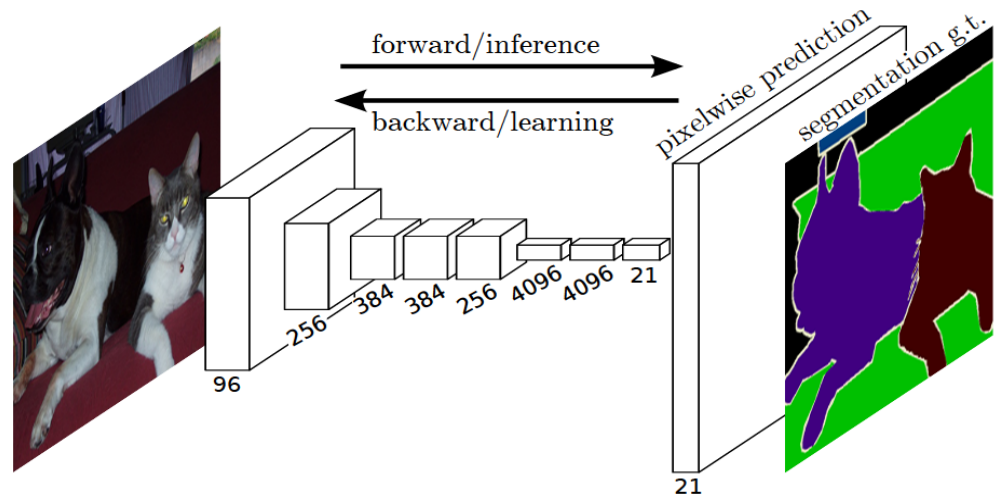

Şekil 4. FCN Mimari Yapısı (Shelhamer vd., 2017) 


\section{3. Çekirdek Segmentasyon Metodolojisi}

Çekirdek segmentasyonu için uygulanan metodoloji ön işleme, eğitim ve değerlendirme olmak üzere üç ön aşamadan oluşmaktadır. İlgili aşamalar sırasıyla alt bölümlerde ele alınmıştır.

\subsection{1. Ön İşleme}

Ön işleme teknikleri, veri setinde bulunan görüntüler arasındaki istenmeyen farklılıkları ortadan kaldırmak veya veriyi farklı tekniklerle çoğaltmak için uygulanır. Renk ve yoğunluk normalleştirme, bu teknikler arasında oldukça popülerdir. Bu teknikle veri setindeki istenmeyen renk farklı1ıkları azaltılmaktadır. Bu teknikler arasında, kanal bazında ortalama çıarma, varyans normalizasyonu (birim varyans) ve piksel değeri aralığı standardizasyonu gibi çeşitli teknikler bulunmaktadır. Bunlarla beraber kontrast artırma-histogram eşitleme teknikleri de kullanılmaktadır. Bu çalışmada da yaygın olarak kullanılan CLAHE (Reza, 2004) tercih edilmiştir.

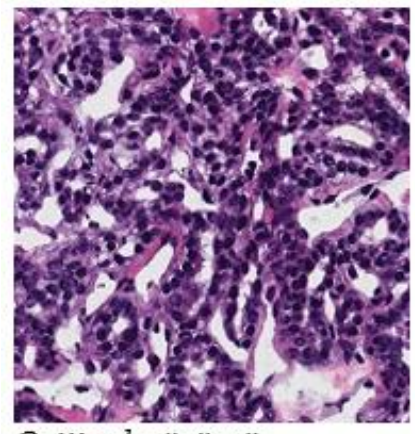

Orijinal görüntü

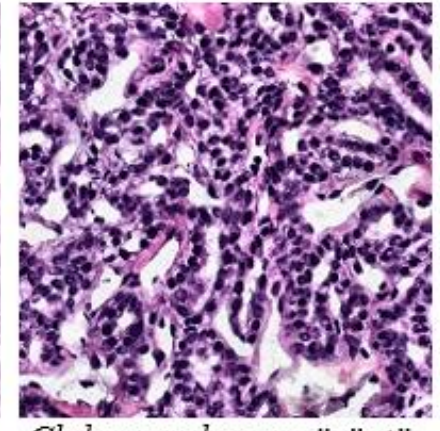

Clahe uygulanan görüntü

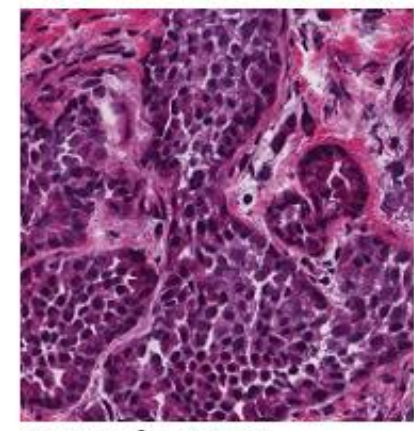

Orijinal görüntü

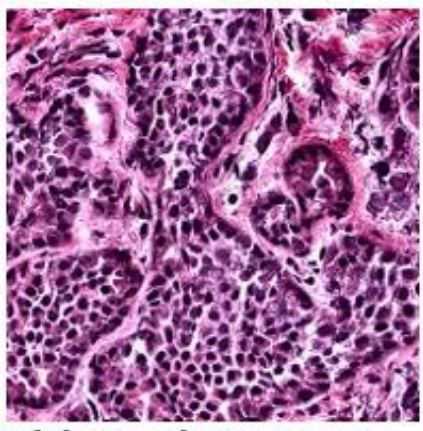

Clahe uygulanan görüntü

Şekil 5. CLAHE uygulaması örnekleri

Histogram eşitleme (HE), görüntünün kontrastını artırmak için kullanılan yaygın bir yöntemdir. HE, yüksek hıza sahip olsa da genellikle aşırı artırma ve yerel bilgi kaybına sebep olmaktadır. Uyarlanabilir histogram eşitleme (AHE) ise görüntünün farklı bölümlerine karşılık gelen birkaç histogramı hesaplayarak yerel kontrastı geliştirebilmektedir. Bununla beraber, uzun hesaplama süresi ve gürültü büyümesi gibi dezavantajları vardır. CLAHE, AHE’nin limitleri sınırlandırılmış modelidir. CLAHE, önceden verilen değerde histogramı kırpması sayesinde büyümeyi önler. Kırpılan değeri aşan kısmı atmayıp, histogram üzerinde eşit olarak dağıtmak avantaj sağlar. Şekil 5 'te gösterilen örnekte, CLAHE uygulandıktan sonra kontrast artırılmış ve eğitilmeden önce anlaşılması kolaylaştırılmıştır.

\subsubsection{Derin Öğrenme}

Bu aşamada, CLAHE algoritması ile ön işlemden geçirilen görüntü setlerinden eğitim seti semantik segmentasyonda kullanılan ilgili derin öğrenme mimarileri ile eğitilmiştir. Eğitim aşamasında eğitim ağ seçenekleri için momentumlu stokastik gradyan inişi (sgdm) kullanılmıştır. Seçeneklerde, ilk öğrenme oranı (initialLearningRate) ' 0,05 ' olarak, en fazla tur (maxEpochs) '100' olarak, öğrenme oranı planlaması (LearnRateSchedule) 'piecewise' olarak, karıştırma (Shuffle) 'every-epoch' olarak, gradyan eşiği (GradientThreshold) '0,05' olarak, grafik çizici (Plots) 'training-progress' olarak, ayrıntı sıklığı (VerboseFrequency) '20' olarak, MiniBatchSize değeriyse ' 1 ' olarak tercih edilmiştir. Bunların dışındaki seçeneklerin varsayılan değerleri tercih edilmiştir. Unet mimarisinde kodlayıcı derinliği (EncoderDepth) değeri ' 3 ' olarak tercih edilmiştir. SegNet mimarisinde kodlayıcı derinliği (EncoderDepth) değeri '4' tercih edilmiştir. DeepLabV3+ mimarisinde ağ olarak 'RESNET18' tercih edilmiştir. FCN mimarisinde model tipi olarak '8s' kullanılmıştır. Sınıflandırma 'çekirdekler' ve 'arkaplan' olarak iki sınıf şeklinde yapılmıştır.

\subsubsection{Değerlendirme}

Bu aşamada eğitilen ilgili mimarinin test görüntü seti üzerinde geçerleme işlemi yapılmaktadır. Performans değerlendirmesi için çalışmada beş farklı değerlendirme kriteri kullanılmıştır:

1) Genel doğruluk oranı, sınıftan bağımsız olarak, sınıflandırılan piksellerin toplam piksel sayısına oranını vermektedir.

2) Ortalama doğruluk oranı, temel gerçeğe (ground truth) göre doğru sınıflandırılan piksellerin o sınıftaki toplam piksel sayısına oranını göstermektedir. Temel gerçek, veri kaynağı, etiket tanımları, işaretli ek etiket açıklamaları hakkında bilgi içeren bir nesnedir. Doğruluk oranı, piksellerin sınıflara ne kadar iyi tanımlandığını görmek için kullanılmaktadır. Ortalama doğruluk, genel doğruluk oranına benzemektedir fakat yanıltıcı da olabilmektedir. Bu yüzden IoU (Intersection over union) ile birlikte kullanılması tavsiye edilmektedir. Doğruluk oranı formülü Eş. 1'de sunulmuştur.

$$
\text { Doğruluk Oranı }=\frac{\text { Doğru Pozitif Sayısı }}{\text { Doğru Pozitif Sayısı + Yanlış Negatif Sayısı }}
$$

3) Intersection over union (IoU), Jaccard benzerlik katsayısı olarak da bilinen, en yaygın ölçüm birimlerinden biridir. Doğru sınıflandırılan piksellerin o sınıftaki toplam temel gerçek ve tahmin edilen piksel sayısına oranıdır. Ortalama IoU ise tüm sınıfların ortalama IoU değeridir. Ortalama IoU oranı formülü Eş. 2'de sunulmuştur. 


$$
I o U=\frac{\text { Doğru Pozitif Sayısı }}{(\text { Doğru Pozitif Sayısı }+ \text { Yanlış Pozitif Sayısı + Yanlış Negatif Sayısı) }}
$$

4) Ağırlıklı IoU oranı, her sınıfın Ortalama IoU değerinin, o sınıftaki piksel sayısına göre ağırlıklandırılmasıyla oluşmaktadır.

5) BF (Boundary F1) skoru, her bir sınıfın tahmin edilen sınırının temel gerçek sınırına ne kadar yakın olduğunu gösterir. Ortalama BF skoruysa, sınıfın tüm görüntüler üzerindeki ortalama BF skorudur. BF Skoru formülü Eş. 3'te sunulmuştur.

$$
\text { BF Skoru }=\frac{\text { Doğru Pozitif Sayısı }}{\text { Doğru Pozitif Sayısı }+\frac{1}{2}(\text { Yanlış Pozitif Sayısı }+ \text { Yanlış Negatif Sayısı })}
$$

\section{Araştırma Sonuçları ve Tartışma}

Deneysel çalışmalar Intel Core i7-9750H 2.6 GHz 6 çekirdek işlemci, 16 GB bellek, 240 GB SSD depolama, Nvidia GeForce GTX 1650 grafik kartından oluşan bilgisayarda ve MATLAB platformu üzerinde gerçekleştirilmiştir. Herbir derin öğrenme mimari için ilgili metodoloji toplam 10 defa koşulmuş ve ilgili sonuçlar ortalamaları alınarak genel doğruluk, ortalama doğruluk, ağırlıklı IoU, BF skor ve çalışma süresi cinsinden Tablo 2'de sunulmuştur. İlgili derin öğrenme mimarilerine ait elde edilen görsel sonuçlar ise Şekil 6'da sunulmuştur. Şekil 6'da 14 adet test görüntüsünün içerisinden 7 adet görüntü kullanılmıştır. Bu görüntüler 1000x1000 piksel boyutta oldukları için küçük boyutlara ölçeklendirildiklerinde detaylar gözden kaçmasını engellemek amacıyla görüntüler 400x400 piksel boyutunda (x,y) koordinatlarına göre $(0,0)$ noktalarından kırpılmıştır. Bunun ardından görüntüler $3 \mathrm{~cm}$ olana dek ölçeklendirilmiş ve Şekil 6'da sunulmuştur.

Tablo 2'ye göre, SegNet diğer mimarilerden daha düşük bir performans sergilemiş ve ortalama IoU olarak \%70'lerin altında kalmıştır. U-Net ise, SegNet mimarisine göre biraz daha iyi bir performans sergilese de çalışma süresi olarak çok diğer mimarilerden çok geride kalmıştır. FCN mimarisi U-Net ve SegNet mimarilerine göre daha iyi değerler elde etmiş ve çalışma süresi bakımından da kabul edilebilir seviyede işlemini tamamlamıştır. Ancak DeepLabV3+ hem değerlendirme kriterleri hem de çalışma süresi bakımından diğer mimarilerden çok iyi performans göstermiştir. İlgili mimariler arasında genel bir sıralama yapılacak olursa DeepLabV3+, FCN, U-Net ve SegNet şeklinde olduğu görülecektir. Ayrıca Şekil 6'daki görsel sonuçlar değerlendirildiğinde de DeepLabV3+ mimarisi SegNet ve U-Net mimarilerinden daha iyi çekirdek segmentasyonu yaptığı görülmektedir. Bazı çekirdeklerin tespit edilmesinde SegNet ve U-Net mimarileri daha iyi performans gösterse de DeepLabV3+ bulduğu hücreleri arkaplandan ayırmakta ve doldurmakta daha başarılıdır.

Tablo 2. Derin ögrenme mimari sonuçlarl

\begin{tabular}{l|c|c|c|c|c|c}
\hline Mimariler & $\begin{array}{c}\text { Ĕgitim } \\
\text { Süresi (dk.) }\end{array}$ & $\begin{array}{c}\text { Genel } \\
\text { Doğruluk }\end{array}$ & $\begin{array}{c}\text { Ortalama } \\
\text { Doğruluk }\end{array}$ & $\begin{array}{c}\text { Ortalama } \\
\text { IoU }\end{array}$ & Ăğırlıklı IoU & BF Skoru \\
\hline$U-N e t$ & 275 & 0,8735 & 0,8758 & 0,7129 & 0,7940 & 0,8822 \\
\hline$F C N$ & 140 & 0,8956 & 0,8635 & 0,7406 & 0,8223 & 0,9063 \\
\hline SegNet & 116 & 0,8644 & 0,8599 & 0,6955 & 0,7811 & 0,8652 \\
\hline DeepLabV3+ & 40 & 0,9155 & 0,8742 & 0,7764 & 0,8509 & 0,9358 \\
\hline
\end{tabular}

\section{Sonuç}

$\mathrm{Bu}$ çalışmada histopatoloji görüntülerde çekirdek segmentasyonu işlemini gerçekleştiren bir metodoloji önerilmiştir. İlgili metodoloji için dört farklı derin öğrenme mimarisi kullanılmış ve bu mimarilerin birbirleri ile karşılaştırmalı analizi yapılmıştır. İlgili sonuçlar neticesinde \%93.58 BF skoru ve \%77.64 ortalama IoU değerleriyle dört mimari arasında en başarılı olan DeepLabV3+ olmuştur. Bununla birlikte aynı parametrelerle yapılan eğitimde DeepLabV3+ mimarisi ile diğer mimariler arasındaki eğitim süresinde de çok büyük fark ortaya çıkmıştır. Her ne kadar literatürdeki çalışmalarda biyomedikal görüntülerde U-Net mimarisinin iyi sonuçlar elde ettiği öne sürülmüş olsa da bu çalışmada görüleceği üzere DeepLabV3+ mimarisi U-Net mimarisine alternatif olarak kullanılabilmesi mümkündür. Bundan sonraki çalışmalarımızda DeepLabV3+ mimarisi üzerine bazı geliştirmeler yapmaya çalışarak çekirdek segmentasyon performansını arttırılması düşünülmektedir. 


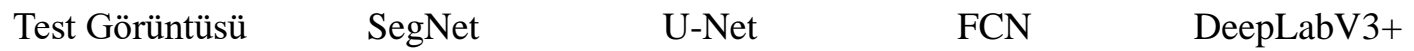

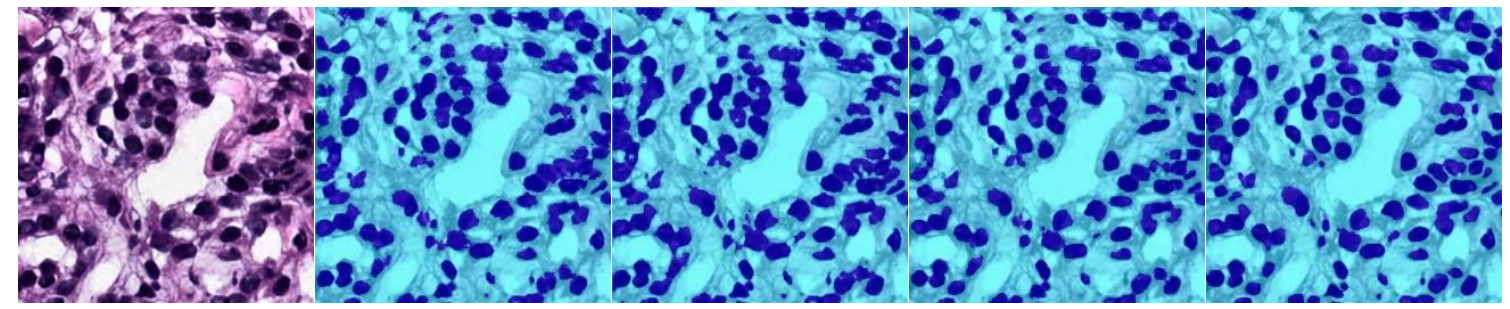

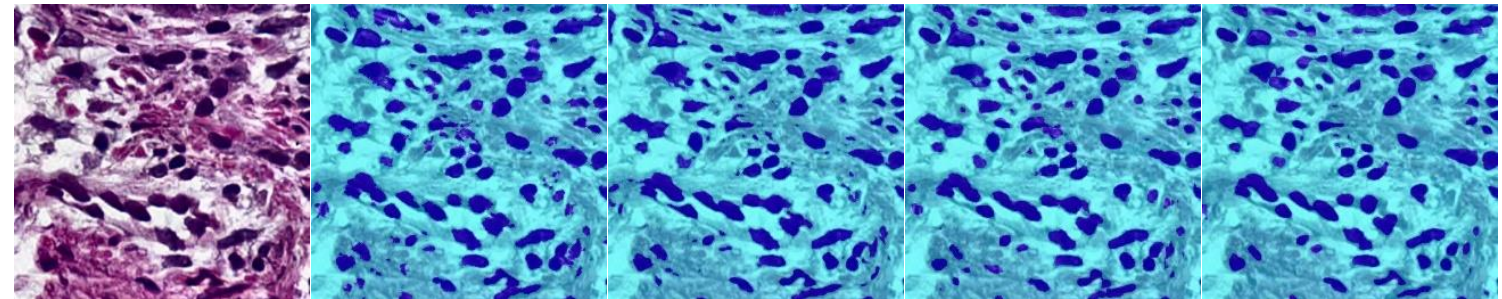

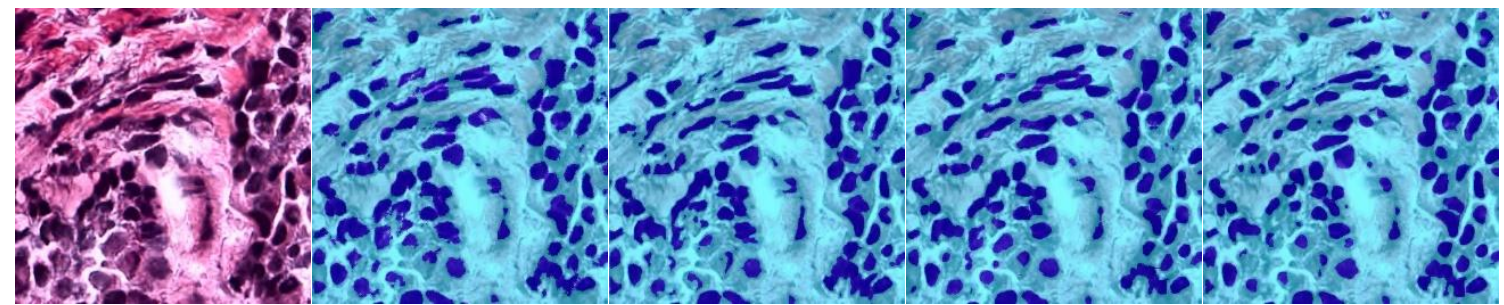

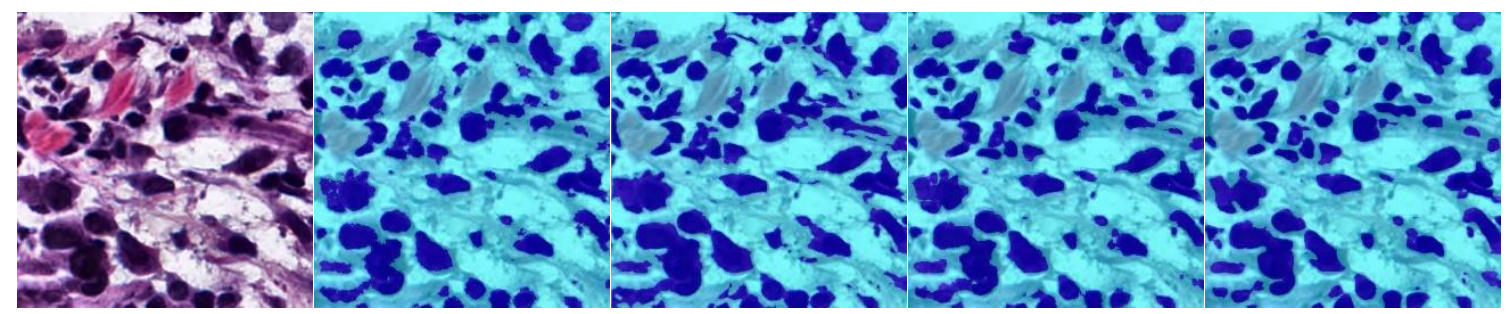

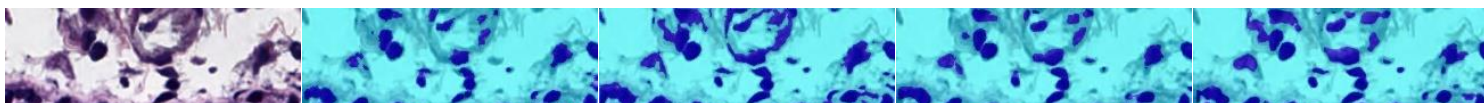

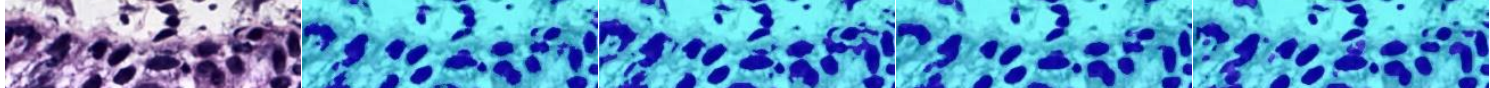

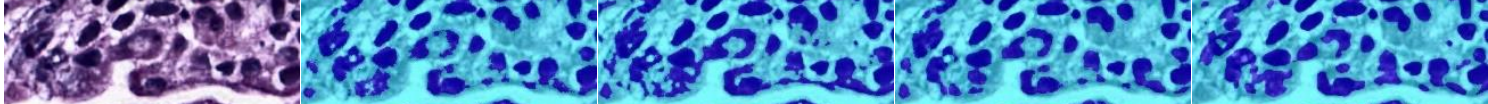

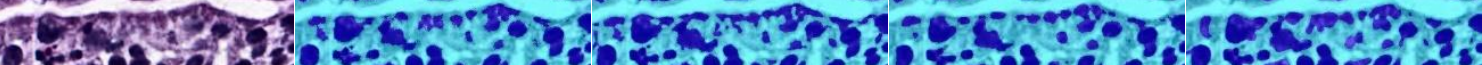

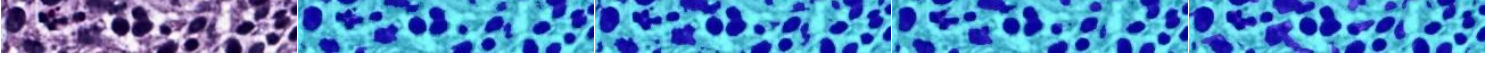
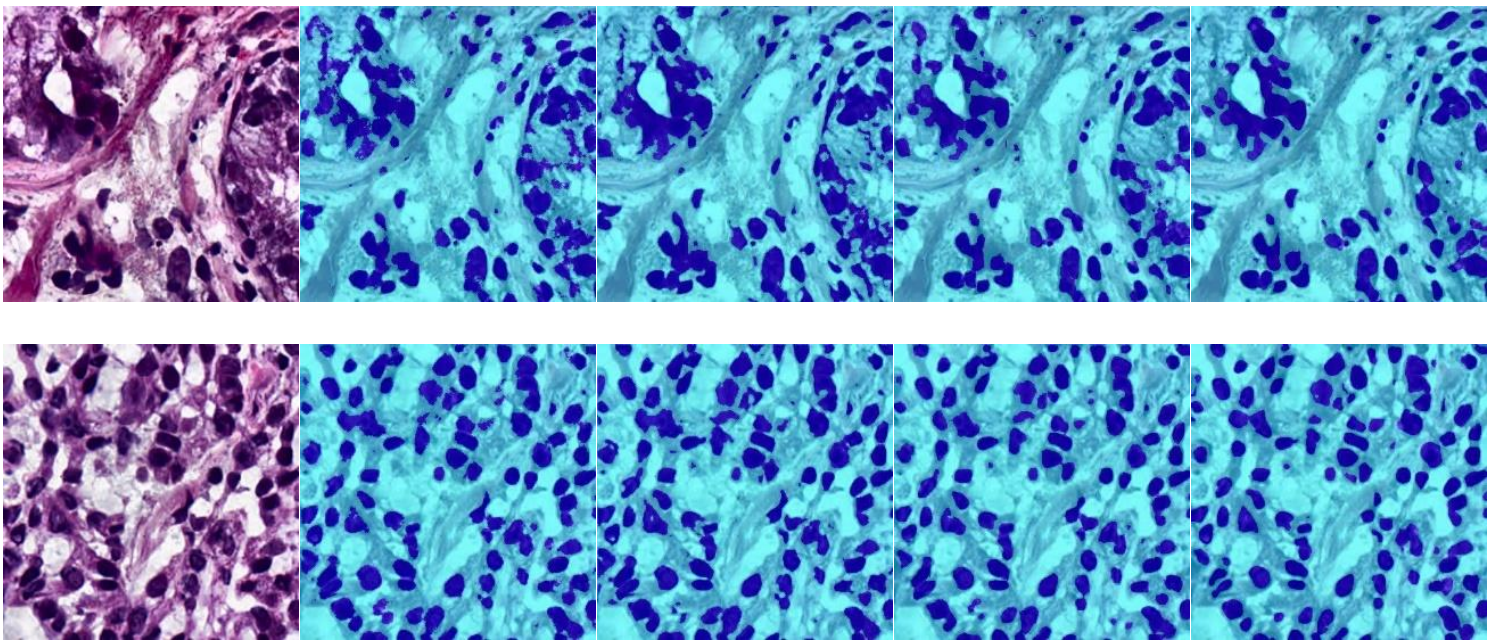

Şekil 6. Test görüntülerinin mimarilere göre çıktı örnekleri 


\section{Kaynakça}

Badrinarayanan, V., Kendall, A., \& Cipolla, R. (2017). SegNet: A Deep Convolutional Encoder-Decoder Architecture for Image Segmentation. IEEE Transactions on Pattern Analysis and Machine Intelligence, 39(12), $2481-2495$. https://doi.org/10.1109/TPAMI.2016.2644615

Chen, L. C., Papandreou, G., Kokkinos, I., Murphy, K., \& Yuille, A. L. (2015). DeepLab: Semantic Image Segmentation with Deep Convolutional Nets, Atrous Convolution, and Fully Connected CRFs. IEEE Transactions on Pattern Analysis and Machine Intelligence, 40(4), 834-848. https://doi.org/10.1109/TPAMI.2017.2699184

Chen, L. C., Zhu, Y., Papandreou, G., Schroff, F., \& Adam, H. (2018). Encoder-decoder with atrous separable convolution for semantic image segmentation. Lecture Notes in Computer Science (Including Subseries Lecture Notes in Artificial Intelligence and Lecture Notes in Bioinformatics), 11211 LNCS, 833-851. https://doi.org/10.1007/978-3-030-01234-2_49

Derraz, F., Beladgham, M., \& Khelif, M. (2004). Application of active contour models in medical image segmentation. International Conference on Information Technology: Coding Computing, ITCC, 2, 675-681. https://doi.org/10.1109/ITCC.2004.1286732

Garcia-Garcia, A., Orts-Escolano, S., Oprea, S., Villena-Martinez, V., \& Garcia-Rodriguez, J. (2017). A Review on Deep Learning Techniques Applied to Semantic Segmentation. 1-23. http://arxiv.org/abs/1704.06857

Jia, Z., Huang, X., Chang, E. I. C., \& Xu, Y. (2017). Constrained Deep Weak Supervision for Histopathology Image Segmentation. IEEE Transactions on Medical Imaging, 36(11), 2376-2388. https://doi.org/10.1109/TMI.2017.2724070

Kumar, N., Verma, R., Anand, D., Zhou, Y., Onder, O. F., Tsougenis, E., Chen, H., Heng, P. A., Li, J., Hu, Z., Wang, Y., Koohbanani, N. A., Jahanifar, M., Tajeddin, N. Z., Gooya, A., Rajpoot, N., Ren, X., Zhou, S., Wang, Q., ... Sethi, A. (2020). A Multi-Organ Nucleus Segmentation Challenge. IEEE Transactions on Medical Imaging, 39(5), 1380-1391. https://doi.org/10.1109/TMI.2019.2947628

Kumar, N., Verma, R., Sharma, S., Bhargava, S., Vahadane, A., \& Sethi, A. (2017). A Dataset and a Technique for Generalized Nuclear Segmentation for Computational Pathology. IEEE Transactions on Medical Imaging, 36(7), 1550-1560. https://doi.org/10.1109/TMI.2017.2677499

Livne, M., Rieger, J., Aydin, O. U., Taha, A. A., Akay, E. M., Kossen, T., Sobesky, J., Kelleher, J. D., Hildebrand, K., Frey, D., \& Madai, V. I. (2019). A U-net deep learning framework for high performance vessel segmentation in patients with cerebrovascular disease. Frontiers in Neuroscience, 13(FEB), 1-13. https://doi.org/10.3389/fnins.2019.00097

Moeskops, P., Wolterink, J. M., van der Velden, B. H. M., Gilhuijs, K. G. A., Leiner, T., Viergever, M. A., \& Išgum, I. (2016). Deep learning for multi-task medical image segmentation in multiple modalities. Lecture Notes in Computer Science (Including Subseries Lecture Notes in Artificial Intelligence and Lecture Notes in Bioinformatics), 9901 LNCS(October), $478-486$. https://doi.org/10.1007/978-3-319-46723-8_55

Park, S. H., Yun, I. D., \& Lee, S. U. (1998). Color image segmentation based on 3-D clustering: Morphological approach. Pattern Recognition, 31(8), 1061-1076. https://doi.org/10.1016/S0031-3203(97)00116-7

Ray, S., \& Turi, R. H. (1999). Determination of number of clusters in k-means clustering and application in colour image segmentation. Proceedings of the 4th International Conference on Advances in Pattern Recognition and Digital Techniques, 137143.

Reza, A. M. (2004). Realization of the contrast limited adaptive histogram equalization (CLAHE) for real-time image enhancement. Journal of VLSI Signal Processing Systems for Signal, Image, and Video Technology, 38(1), 35-44. https://doi.org/10.1023/B:VLSI.0000028532.53893.82

Ronneberger, O., Fischer, P., \& Brox, T. (2015). U-net: Convolutional networks for biomedical image segmentation. Lecture Notes in Computer Science (Including Subseries Lecture Notes in Artificial Intelligence and Lecture Notes in Bioinformatics), 9351, 234241. https://doi.org/10.1007/978-3-319-24574-4_28

Roth, H. R., Shen, C., Oda, H., Oda, M., Hayashi, Y., Misawa, K., \& Mori, K. (2018). Deep learning and its application to medical image segmentation. 1-6. https://doi.org/10.11409/mit.36.63

Shelhamer, E., Long, J., \& Darrell, T. (2017). Fully Convolutional Networks for Semantic Segmentation. IEEE Transactions on Pattern Analysis and Machine Intelligence, 39(4), 640-651. https://doi.org/10.1109/TPAMI.2016.2572683

Simonyan, K., \& Zisserman, A. (2015). Very deep convolutional networks for large-scale image recognition. 3rd International Conference on Learning Representations, ICLR 2015 - Conference Track Proceedings, 1-14.

Tobias, O. J., \& Seara, R. (2002). Image segmentation by histogram thresholding using fuzzy sets. IEEE Transactions on Image Processing, 11(12), 1457-1465. https://doi.org/10.1109/TIP.2002.806231

Wang, G., Li, W., Zuluaga, M. A., Pratt, R., Patel, P. A., Aertsen, M., Doel, T., David, A. L., Deprest, J., Ourselin, S., \& Vercauteren, T. (2018). Interactive Medical Image Segmentation Using Deep Learning with Image-Specific Fine Tuning. IEEE Transactions on Medical Imaging, 37(7), 1562-1573. https://doi.org/10.1109/TMI.2018.2791721

Zhang, X., Shan, Y., Wei, W., \& Zhu, Z. (2010). An image segmentation method based on improved watershed algorithm. Proceedings - 2010 International Conference on Computational and Information Sciences, ICCIS 2010, 1(4), $258-261$. https://doi.org/10.1109/ICCIS.2010.69

Zhou, X., Yamada, K., Takayama, R., Zhou, X., Hara, T., Fujita, H., Wang, S., \& Kojima, T. (2018). Performance evaluation of 2D and $3 D$ deep learning approaches for automatic segmentation of multiple organs on CT images. $10575,83$. https://doi.org/10.1117/12.2295178 